\title{
Study of knowledge, attitude and practice of peripheral intravenous cannulation among interns at Mc Gann teaching district hospital, Shivamogga: a descriptive cross-sectional study
}

\author{
Vedavathi Hanumaiah, Eshanu H. Shastry*, Shreenivas Revankar
}

Department of Pharmacology, Shivamogga Institute of Medical Sciences, Shivamogga, Karnataka, India

Received: 16 June 2020

Revised: 08 July 2020

Accepted: 09 July 2020

*Correspondence:

Dr. Eshanu H. Shastry,

Email: eshanu10@yahoo.com

Copyright: (c) the author(s), publisher and licensee Medip Academy. This is an open-access article distributed under the terms of the Creative Commons Attribution Non-Commercial License, which permits unrestricted non-commercial use, distribution, and reproduction in any medium, provided the original work is properly cited.

\begin{abstract}
Background: Peripheral intravenous cannulation (PIVC) is a first-choice vascular device, commonly performed clinical skill by junior medical doctors and interns in hospital. Improper technique of PIVC can lead to pain, stress, increased chance of infection. Thus, practising the appropriate PIVC technique is vital for interns. This study is conducted to analyse the understanding and necessity for training required to perform accurate PIVC. The objective of this descriptive cross-sectional study was conducted to determine and identify the level of knowledge, attitude and practice regarding PIVC among the interns of Mc Gann teaching district hospital, Shivamogga.

Methods: A validated structured questionnaire containing 20 questions regarding PIVC in knowledge, attitude and practice (KAP) format was distributed in hand among 109 interns affiliated to this institution. Descriptive statistics were used to illustrate the results in the form of number and percentage. Chi- square and one-way ANOVA was used to analyse the result. SPSS 21.0 was used.

Results: $74 \%$ of the participating interns had proper knowledge about the vein commonly used for PIVC. Only $39 \%$ of the interns answered that PIVC was an aseptic technique. 108 participants had knowledge about the common complication due to PIVC which is thrombophlebitis. 2/3rd of the interns was supervised on their first PIVC procedure by a nurse. $94.4 \%$ of the interns were instructed regarding the hand washing technique during PIVC.

Conclusions: Need for learning module and training programs to ensure the interns have knowledge PIVC technique, complications and management.
\end{abstract}

Keywords: Peripheral intravenous cannulation, Thrombophlebitis, Hand washing technique

\section{INTRODUCTION}

Peripheral intravenous cannulation (PIVC) is a common technique used in the modern-day medicine, especially in the intensive care unit, where a venous access is achieved via peripheral veins. This technique is used to administer fluids, drugs, and blood products to the patient in case of an emergency. ${ }^{1}$ By inserting PIVC, blood samples can be taken multiple times for laboratory analysis. These days, the use of PIVC in radiology is rapidly growing. The preferable route of administration of contrast material is via a peripheral iv cannula, with powered injectors allowing reliable delivery of rapid flow rates. ${ }^{2}$ PIVC technique is also used in emergency conditions like Tension pneumothorax, where cannula is inserted into $2^{\text {nd }}$ intercostal space. ${ }^{3}$ Over a billion of PIVC are inserted in hospitals each year, but global prevalence of using PIVC is lacking. ${ }^{4}$ Although, a study conducted in the year 2015, showed that global sales of the PIVC have been reported to be approximately 1.2 billion. ${ }^{5}$ The demand for 
peripheral I.V. catheters is increasing due to increasing prevalence of chronic and lifestyle associated diseases. Though the technique gains an easy and quick access into the venous system, poses a lot of challenges due to its faulty insertion.

The appropriate knowledge should be present prior to the procedure consider catheter gauge, number of lumens, length, type of therapy, site of insertion, risk of complications including infection, and patient factors. ${ }^{6}$ Before the procedure, interns should be have proper education targeting key components of PIVC care including dressings, catheter duration, line care and infection control measures. ${ }^{7}$ Catheter related complications are very common and quite serious, yet preventable. These devices can lead patients to experience multiple complications during insertion, management and maintenance of PIVC at a hospital setting. ${ }^{8}$ Faulty technique leads to a lot of complications namely, obstruction, local site infections, phlebitis, extravasation, air embolism, haemorrhage, fungal and bacterial infection etc. Multiple attempts of needle insertion can lead to pain stress and discomfort to the patient as well. These complications also depend on other factors like type of catheter, catheter manipulation and health status of patient. Hence, proper care should be taken while inserting the catheter. ${ }^{9}$

In our institution, PIVC is a commonly performed clinical skill by interns. Usually, catheters are inserted in case of an emergency where the interns fail to maintain the proper technique of PIVC. There is a gap in the knowledge and awareness about the procedure of PIVC. Hence, the study was conducted with aim to assess the level of understanding and knowledge about the technique of PIVC and the complications associated with it. We also felt a need to understand the level of education and formal training received by the interns before they performed this clinical skill on a patient.

\section{METHODS}

\section{Study design}

This descriptive cross-sectional study involved 109 interns affiliated to Mc Gann teaching district hospital, Shivamogga. The study was completed within duration of 1 month from $15^{\text {th }}$ November to $14^{\text {th }}$ December 2019.

Informed consent was obtained from all the participants before conducting the study. The participants were free to deny from participating in the study. Before the commencement of the study, the questionnaires were distributed among 10 experts from various departments of this institution and content validity ratio (CVR) was determined.

Only the questions with CVR $>0.62$ were included. ${ }^{10}$ The knowledge, attitude and practice were evaluated by a semi-structured validated, pre-tested questionnaire in
English language. These questionnaires were distributed by the investigator to all the study participants by hand. The participants were instructed to fill all the answers accurately as per their knowledge. The questionnaire consisted of 20 questions in total, designed to capture three main aspects of KAP study, namely "knowledgebased", "attitude-based" and "practice-based". ${ }^{11}$ This study was conducted after receiving an ethical approval from the Institutional Ethics Committee.

\section{Statistical analysis}

We performed descriptive statistics to illustrate the results in form of numbers and percentage. All the information gathered from the questionnaire were coded into variables. Chi square test and one-way ANOVA were used to analyse the result. For each test, p-value less than 0.05 was considered significant. Statistical package for social sciences software 21.0 (SPSS 21) was used for the analysis. Results are reported according to the strengthening the reporting of observational studies in epidemiology reporting guidelines for observational studies. $^{12}$

\section{RESULTS}

\section{Assessment of knowledge of PIVC among participants}

The knowledge about the appropriate veins to be used for intravenous cannulation procedure was tested among the interns. The results showed that majority of interns had proper knowledge regarding the vein commonly used for intravenous cannulation $74 \%$. On assessing the knowledge regarding most ideal site for cannula insertion, around 100 interns $91.7 \%$ answered upper-limb and around 65 interns $59.6 \%$ preferred non-dominant site.

Varied responses were given when the interns were asked about the gauge of the cannula commonly used for intravenous fluid administration. Around $62.4 \%$ of interns answered that they would use a $20 \mathrm{G}$ cannula, $23 \%$ said they use $18 \mathrm{G}$ cannula. Only around $12.8 \%$ of them said $22 \mathrm{G}$ cannula to be used for the purpose of fluid administration, while it was answered as $16 \mathrm{G}$ by about $1.8 \%$ of the study participants. A total of sixty-one percentage of interns said PIVC is a clean procedure with regards to the control of infection during the procedure while the rest $39 \%$ said it was an aseptic technique.

While assessing the knowledge regarding the various complications associated with the PIVC technique, it was found that $99 \%$ of the participants had knowledge about thrombophlebitis and occlusion of the vein. The responses to other complications due to PIVC were varied as mentioned in the table (Table 1).

With the aim to assess the knowledge the interns had about complication due to age and gender criteria, two questions were directed to know the same (Figure 1 and 2). 


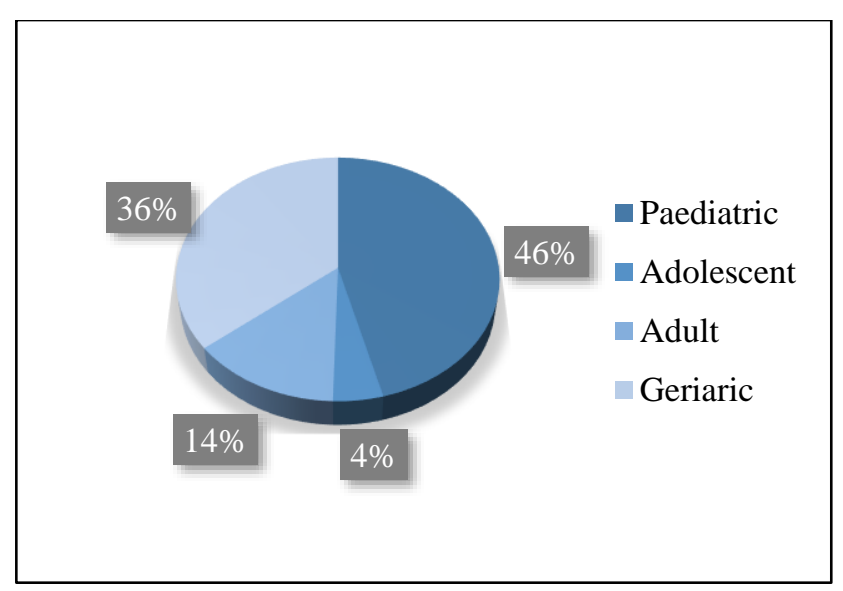

Figure 1: Age factor related complications.

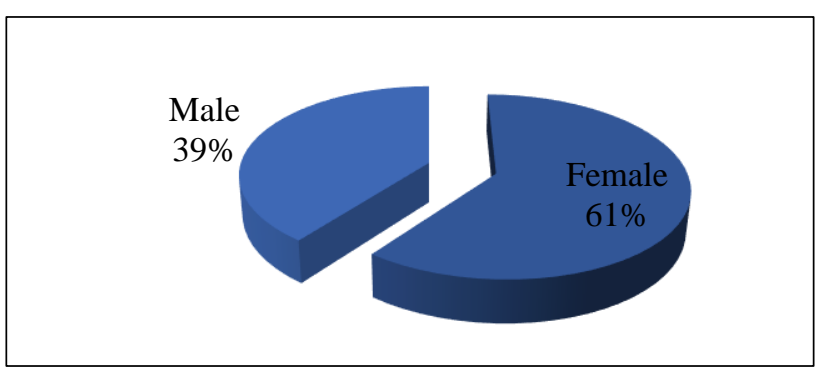

Figure 2: Gender factor related complications.

\section{Assessment of attitude of PIVC among participants}

The attitude of interns towards the PIVC was evaluated based upon their training during the under graduate course and them performing the procedure on mannequins and patients (Table 2). Around $94.5 \%$ of interns had at least done PIVC once and none of them had practiced it on a mannequin prior to performing on a patient.

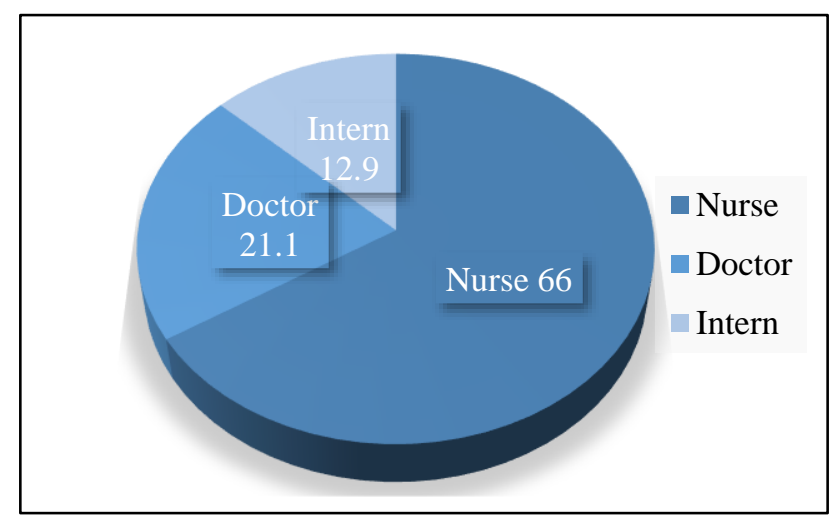

Figure 3: Supervision during IV cannulation.

It also came to our notice that around $50 \%$ of the study participants have performed the procedure less than 15 times. $66 \%$ of the interns were supervised on their PIVC procedure by a nurse whereas $21.1 \%$ of interns had their supervision done by a medical doctor. Only $12.9 \%$ were supervised by a co-intern during the procedure of cannulation (Figure 3).

Table 1: Assessment of knowledge regarding PIVC complication.

\begin{tabular}{|lll|}
\hline Complication & Yes & No \\
$\mathbf{N}(\%)$ & N $(\%)$ \\
\hline Thrombophlebitis & $108(99)$ & $1(1)$ \\
\hline Infiltration & $92(84)$ & $17(15.5)$ \\
\hline Hematoma & $100(91.7)$ & $9(8.2)$ \\
\hline Extravasation of drug & $87(79.81)$ & $22(20.1)$ \\
\hline Air embolism & $96(88)$ & $13(12)$ \\
\hline $\begin{array}{l}\text { Intra-arterial injection } \\
\text { of drug }\end{array}$ & $63(57.7)$ & $46(42.2)$ \\
\hline Pressure injury & $25(22.9)$ & $84(77)$ \\
\hline $\begin{array}{l}\text { Anaphylaxis/allergic } \\
\text { reaction }\end{array}$ & $56(51.3)$ & $53(48.6)$ \\
\hline Hypervolemia & $20(18.3)$ & $89(81.6)$ \\
\hline Skin necrosis & $25(22.9)$ & $84(77)$ \\
\hline Nerve damage & $34(31.1)$ & $75(68.8)$ \\
\hline Occlusion & $108(99)$ & $1(1)$ \\
\hline
\end{tabular}

Table 2: Assessment of attitude regarding PIVC procedure.

\begin{tabular}{|lll|}
\hline \multicolumn{1}{|l|}{$\begin{array}{l}\text { Yes } \\
\text { Question }\end{array}$} & $\begin{array}{l}\text { No } \\
\text { N }(\%)\end{array}$ \\
\hline $\begin{array}{l}\text { During your MBBS course } \\
\text { was any formal training } \\
\text { given on IV cannulation } \\
\text { procedure? }\end{array}$ & $2(1.8)$ & $\begin{array}{l}107 \\
(98.2)\end{array}$ \\
\hline $\begin{array}{l}\text { Have you performed an IV } \\
\text { cannulation on a } \\
\text { mannequin? }\end{array}$ & $0(0)$ & 109 \\
\hline $\begin{array}{l}\text { Have you ever performed } \\
\text { IV cannulation on a } \\
\text { patient? }\end{array}$ & $103(94.5)$ & $6(5.5)$ \\
\hline $\begin{array}{l}\text { Was documentation of } \\
\text { catheter insertion done? }\end{array}$ & $25(22.9)$ & $\begin{array}{l}84 \\
(77.06)\end{array}$ \\
\hline
\end{tabular}

$\mathrm{IV}=$ intravenous.

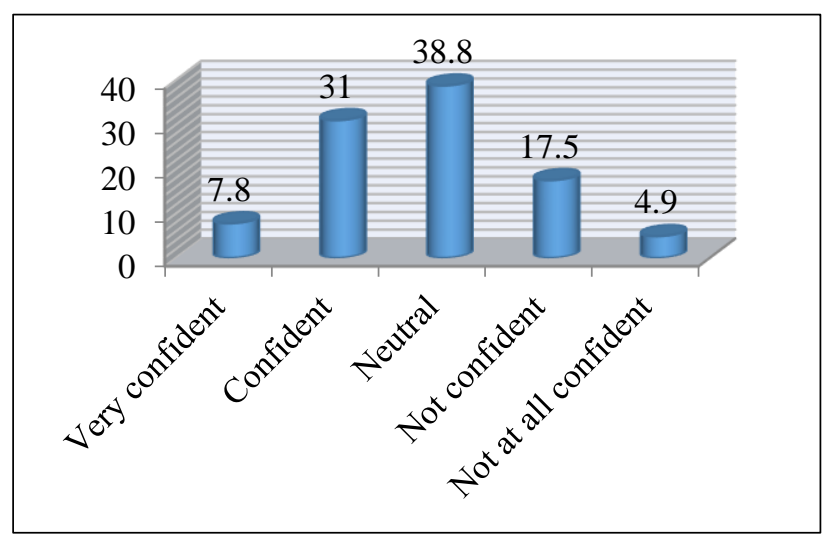

Figure 4: Level of confidence to perform PIVC. 
The level of confidence among the interns to perform a PIVC procedure were classified into 5 groups namely very confident, confident, neutral, not confident and not at all confident (Figure 4). The number of cannulas that the interns had inserted was recorded using descriptive statistics. Analysis of the association between the level of confidence to perform a PIVC procedure and the number of cannulas inserted was done. One-way ANOVA test was done to check for association between the number of cannulas inserted and the confidence to perform the procedure. The $\mathrm{p}$ value for the test was $<0.001$ which showed that there was significant association between the 2 variables

\section{Assessment of practice of PIVC among participants}

A total of 6 questions were directed to assess the practice domain of PIVC. $94.4 \%$ of the participants responded that they were instructed about hand washing technique during the procedure of PIVC (Table 3). The interns were also asked about the how many times hand washing was advised which included prior to PIVC, after PIVC or both (Figure 5). $79.8 \%$ of the interns replied with an affirmative answer for the use of gloves prior to PIVC. The two common methods utilized for vein palpation according to the study were open and close of fist (91.7\%) and vein tapping (Figure 6). All 109 participants had followed skin antisepsis procedure prior to PIVC (Figure 7). One of the questions was directed to know in whom was the PIVC easier, it was found that $80 \%$ of the interns found it easy to locate a vein in a thin patient.

Table 3: Assessment of practice regarding PIVC procedure.

\begin{tabular}{|lll|}
\hline Practice domain & $\begin{array}{l}\text { Yes } \\
\text { N (\%) }\end{array}$ & $\begin{array}{l}\text { No } \\
\text { N }(\%)\end{array}$ \\
\hline $\begin{array}{l}\text { Were you advised about } \\
\text { hand washing }\end{array}$ & $103(94.4)$ & $6(5.5)$ \\
\hline $\begin{array}{l}\text { Use of gloves prior to } \\
\text { PIVC }\end{array}$ & $87(79.8)$ & $22(20.1)$ \\
\hline
\end{tabular}

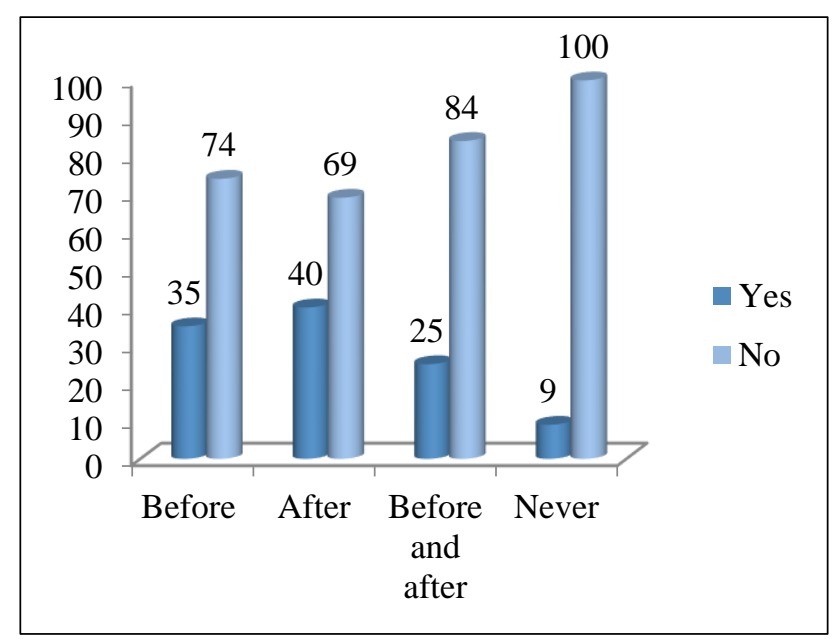

Figure 5: Hand washing technique performed.

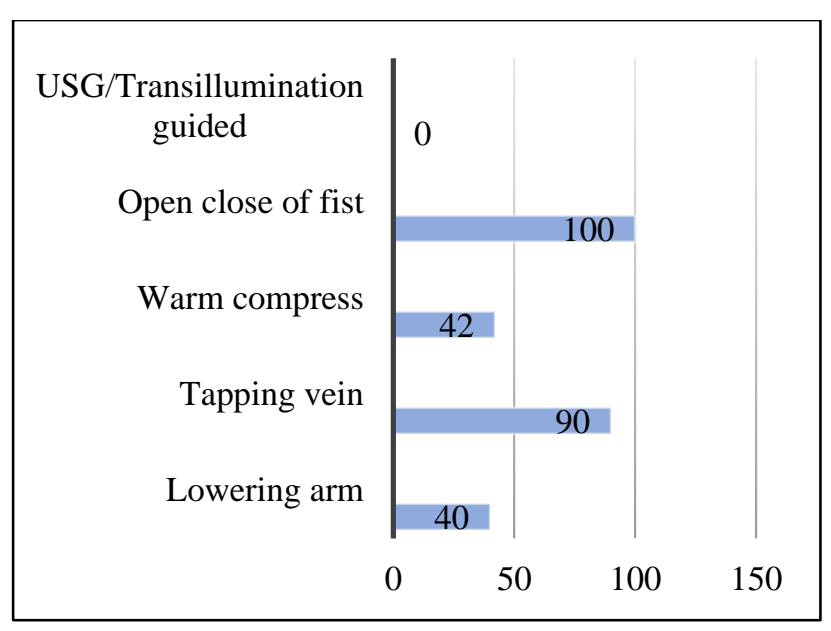

Figure 6: Vein palpation method practiced.

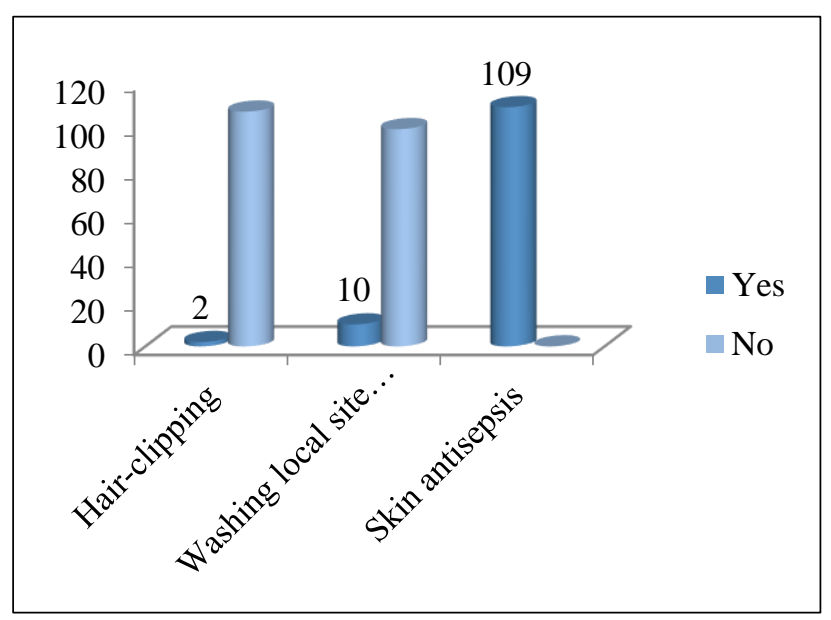

Figure 7: Local skin preparation method practiced.

\section{DISCUSSION}

This study was conducted with a motive to understand the level of understanding and the knowledge the interns have regarding the PIVC. The questions were directed towards three major domains: knowledge, attitude and practice. It was found that overall knowledge, attitude and practice regarding PIVC technique was found to be limited among the interns. Though a routine practice, the interns lacked proper the technique and the idea of asepsis required during the procedure.

Although intravenous therapy is one of the most commonly performed procedures in hospitalized patients, it remains susceptible to both infectious and noninfectious complications. The complications due to faulty technique can be categorised to minor and major based on the severity of the symptoms. Minor complications include catheter occlusions, accidental removals, fear of sharp catheters (needle phobia) and pain. Whereas, the major complications are thrombophlebitis, infection, extravasation, hematoma and even skin injuries. ${ }^{13}$ Complications may be as a result of various factors namely, the size of the catheter, insertion site preparation, 
type of infusion, insertion technique, catheter dwell time, dressing type and the insertion site. ${ }^{7}$ Measures should be taken to reduce the risk of these complication by all health care personnel. Such a technique requires supervision and training by the experienced health personnel during the first few days of internship. ${ }^{11}$ It was found that the interns neither received formal training nor practiced the procedure on a mannequin before handling the patients. If this situation prevails even in the future, the number of adverse effects related to the faulty technique of PIVC will increase tremendously.

It is the duty of an intern to assess specific patient factors such as pre-existing catheters, anatomic deformity, the relative risk of mechanical complications and the risk of infection. The distal areas of the upper extremities are optimal for site for insertion of a Peripheral venous cannula. Subsequent catheterisation should be made proximal to the previously catheterised site. Catheters inserted into the lower limbs have a greater risk of complications than the upper limbs. ${ }^{7,14}$ Placement of the PIVC in non-flexion areas such as the forearm to provide stability for the device reduces patient discomfort also reduce movement of the catheter at the insertion site and within the blood vessel. ${ }^{15}$ The basilic or cephalic veins on dorsal forearm are the preferred site for catheterisation. Our study showed that the interns had adequate knowledge regarding the site of catheter insertion. Majority of the study participants answered that the upper limb and the non-flexion site are ideal for insertion of PIVC.

The size of the catheter to be used will depend on the medical emergency situation. Small size catheters are generally used first as it allows less resistance to blood flow and are associated with lesser complications. Large catheters, such as 14- and 16-gauge catheters are used in acute situations for fluid resuscitation. Other variables that may influence the size of the catheter used include age-related vessel size, the need for pressurized boluses for administration of contrast material or medication, and the viscosity of the fluid to be infused. $22 \mathrm{G}$ cannula is the most suitable for PIVC. ${ }^{16,17}$ Proper choice of the cannula gauge by an intern might reduce the complications faced due to PIVC. Interestingly, our study showed that very few interns knew about the appropriate size selection of cannula.

One of the main complications of PIVC is phlebitis, inflammation of the vein and when phlebitis is combined with thrombus formation, it is called thrombophlebitis. It occurs due to mechanical irritation of the vascular walls by materials infused, stiff catheter material or bacterial colonisation damages the endothelium. ${ }^{18}$ The insertion of a PIVC provides a potential portal of entry for bacteria to cross from an unsterile external environment to the normally sterile blood, which can become contaminated by healthcare workers' or patients' skin flora during the procedure. The most common bacteria associated with thrombophlebitis are coagulase-negative Staphylococci and Staphylococcus aureus. ${ }^{19}$ Our study revealed that the interns were quite informed about the cause, signs and symptoms of thrombophlebitis.

Tissue infiltration and extravasation of the administered fluid is yet another complication associated with the faulty placement of cannulas, its dislodgement or due to erosion/displacement of the cannula. The fluid/drug leaks into the surrounding tissue and causes tissue damage; diagnosed by local oedema, cool skin, reduced fluid flow rate, burning pain and discomfort experienced by the patient. Hence, proper placement of cannula has to be ensured. ${ }^{20}$ Many other common complications include hematoma, occlusion of the cannula and air embolism. Our study revealed that interns were quite aware of the common adverse effects due to faulty procedure, yet it is the duty of the intern to have an adequate knowledge of entire spectrum of complications and ways to tackle the problem.

Hand-washing is a simple yet most important step before performing any of the clinical procedure. Just a few seconds of hand hygiene can decrease complications related to PIVC. Use of chlorhexidine based antiseptic solution, pair of sterile gloves and an appropriate PPE poses less risk. $^{7}$ It is recommended to wash the hands before and after the procedure. The recommended method of skin antisepsis is a back and forth scrubbing motion with $2 \%$ chlorhexidine gluconate in $70 \%$ isopropyl alcohol or povidone iodine in alcohol for patients with sensitivity to chlorhexidine, then allow the site to air dry prior to the insertion of a catheter. Even washing the local site with soap and water together with hair clipping is followed. ${ }^{7,21}$ Hence, improper hygiene leads to most important and serious complication, thrombophlebitis (2-80\%). Our questionnaire attempted to understand the present scenario that happens in our hospital. Majority of the interns were not practicing proper handwashing and were not aware of the importance of the hand and skin asepsis.

Most of the KAP studies on PIVC technique were done on nurses. But we chose interns for the study as most of the basic procedure in our institution including PIVC, electrocardiogram, urinary catheterisation etc. are done by the interns. Here, we have tried to understand the level of knowledge, attitude and practice in deep so that further implementation of guidelines could be possible. The studies conducted previously were carried on interns during their initial days of internship, whereas, our study was done when most of the interns had completed a significant time of their internship course.

\section{CONCLUSION}

The study showed that the interns were not very well trained in performing the clinical skill of PIVC. The knowledge about the complication associated with faulty technique and the ways to manage it was very limited. The concept of hand-washing and maintenance of asepsis 
was found to be poor. Concluding from the study, procedural skills such as PIVC should be trained in skill laboratories as practicing on real patients can cause ethical issues. Constant supervision and mentoring should be assured in the initial few days of hospital while they performed PIVC. The hospital management should conduct several skill-based activities where the interns can perform the technique on mannequin during the first weeks of their internship. A structured learning module for the interns ensuring the adequate knowledge imparted regarding the procedure, complication and management has to be given. Furthermore, interns can also educate patients to look out for early signs of infection at the cannula site to help early detection.

\section{ACKNOWLEDGEMENTS}

The Authors of the study are thankful to the management of Shivamogga Institute of Medical Sciences and Mc Gann Teaching Hospital, Shivamogga for their help and co-operation through the study.

\section{Funding: No funding sources}

Conflict of interest: None declared

Ethical approval: The study was approved by the Institutional Ethics Committee (SIMS/IEC/478/2019-20)

\section{REFERENCES}

1. Decker K, Ireland S, O'Sullivan L, Boucher S, Kite L, Rhodes D, et al. Peripheral intravenous catheter insertion in the Emergency Department. Australasian Emergency Nursing J. 2016;19(3):138-42.

2. Plumb AA, Murphy G. The use of central venous catheters for intravenous contrast injection for CT examinations. British J Radiology. 2011;84(999):197-203.

3. Martin M, Satterly S, Inaba K, Blair K. Does needle thoracostomy provide adequate and effective decompression of tension pneumothorax. J Trauma Acute Care Surg. 2012;73(6):1412-7.

4. Alexandrou E, Barruel RG, Carr PJ, Frost S, Inwood $\mathrm{S}$, Higgins $\mathrm{N}$, et al. International prevalence of the use of peripheral intravenous catheters. J Hospital Medicine. 2015;10(8):530-3.

5. Newswire PR. Global peripheral I.V. catheter market 2014-2018. Available http://www.prnewswire.com/news-releases/globalperipheral-iv-catheter-market-2014-2018257019061.html. Accessed on 28 April 2015.

6. O'grady NP, Alexander M, Burns LA, Dellinger EP, Garland J, Heard SO, et al. Guidelines for the prevention of intravascular catheter-related infections. Clin Infectious Diseases. 2011;52(9):16293.

7. Peripheral intravenous catheter (PIVC). Available at https://www.health.qld.gov.au/_data/assets/pdf_file/ 0025/444490/icare-pivc-guideline.pdf. Accessed on 20 October 2018.
8. Mavillard BI, Calero RMA, Gomez PJ, Garcia PG, Fernandez FI, Sanchez CE. Incidence of peripheral intravenous catheter failure among inpatients: variability between microbiological data and clinical signs and symptoms. Anti-microbial Resistance Infection Control. 2019;8(1):124.

9. Makafi SA, Marfega MA. Peripheral Intravenous Catheter (PIVC) Related Local Complications among Patients in KFCH-Jizan. Adv Practice Nurs. 2017;2(138):2573-347.

10. Lawshe $\mathrm{CH}$. A quantitative approach to content validity. Personnel Psychology. 1975;28(4):563-75.

11. Carr PJ, Glynn RW, Dineen B, Devitt D, Flaherty G, Kropmans TJ, et al. Interns attitudes to IV cannulation: a KAP study. British J Nursing. 2011;20(4):15-20.

12. Elm VE, Altman DG, Egger M, Pocock SJ, Gotzsche PC, Vandenbroucke JP. The Strengthening the Reporting of Observational Studies in Epidemiology (STROBE) statement: guidelines for reporting observational studies. Annals Internal Med. 2007;147(8):573-7.

13. Abolfotouh MA, Salam M, Mustafa ABDW, Balkhy $\mathrm{HH}$. Prospective study of incidence and predictors of peripheral intravenous catheter-induced complications. Therapeutics Clin Risk Management. 2014;10:993.

14. Ganeshan A, Warakaulle DR, Uberoi R. Central venous access. Cardiovascular Interventional Radiology. 2007;30(1):26-33.

15. Alexandrou E, Barruel GR, Carr PJ, Dip HE, Niall Higgins N, Lin F, et al. Use of Short Peripheral Intravenous Catheters: Characteristics, Management, and Outcomes Worldwide. J Hosp Med. 2018.

16. Portal MR. Peripheral intravenous (IV) device management. R Child. 1997;70:99-101.

17. Ortega R, Sekhar P, Song M, Hansen CJ, Peterson L. Peripheral intravenous cannulation. N Engl J Med. 2008;359(21):26-9.

18. Lee S, Kim K, Kim JS. A Model of Phlebitis Associated with Peripheral Intravenous Catheters in Orthopedic Inpatients. Int J Environmental Res Public Health. 2019;16(18):3412.

19. Urbanetto JD, Peixoto CG, May TA. Incidence of phlebitis associated with the use of peripheral IV catheter and following catheter removal. Revista latino-americana de enfermagem. 2016;24.

20. Kaur P, Rickard C, Domer GS, Glover KR. Dangers of Peripheral Intravenous Catheterization: The Forgotten Tourniquet and Other Patient Safety Considerations. Vignettes Patient Safety. 2019;4.

21. Clohert J, Eichenwald E, Hansen A, Stark A. Manual of intensive care. Lippincott Williams and Wilkins; 2012.

Cite this article as: Hanumaiah V, Shastry EH, Revankar S. Study of knowledge, attitude and practice of peripheral intravenous cannulation among interns at Mc Gann teaching district hospital,

Shivamogga: a descriptive cross-sectional study. Int J Basic Clin Pharmacol 2020;9:1204-9. 